\title{
Vaccine-induced immune thrombotic thrombocytopenia and spike protein
}

Manuela De Michele ( M.DeMichele@policlinicoumberto1.it)

Sapienza University of Rome https://orcid.org/0000-0002-3928-4309

Paola Piscopo

Department of Neuroscience, Istituto Superiore di sanità

Alessio Crestini

Department of Neuroscience, Istituto Superiore di sanità

Roberto Rivabene

Department of Neuroscience, Istituto Superiore di sanità

Giulia d'Amati

Martina Leopizzi

Department of Medico-surgical sciences and Biotechnologies, Sapienza University of Rome

Lucia Stefanini

Department of Translational and Precision Medicine, Sapienza University of Rome

Davide Flego

Department of Translational and Precision Medicine, Sapienza University of Rome

Fabio Pulcinelli

Department of Experimental Medicine, Sapienza University of Rome

Antonio Chistolini

Hematology, Department of Translational and Precision Medicine, Sapienza University of Rome https://orcid.org/0000-0002-2593-1376

Marta lacobucci

Neuroradiology Unit, Department of Human Neurosciences, Sapienza University of Rome https://orcid.org/0000-0002-3911-3278

Oscar Schiavo

Stroke Unit, Emergency Department, Sapienza University of Rome

Irene Berto

Department of Human Neurosciences, Sapienza University of Rome

Ettore Nicolini

Stroke Unit, Emergency Department, Sapienza University of Rome https://orcid.org/0000-0002-8481-6327

Luca Petraglia

Department of Human Neurosciences, Sapienza University of Rome

Maria Teresa Di Mascio

Stroke Unit, Emergency Department, Sapienza University of Rome

Danilo Toni

Department of Human Neurosciences, Sapienza University of Rome

Article

Keywords: vaccine-induced immune thrombotic thrombocytopenia, DNA-based vaccine, spike protein, COVID-19

Posted Date: September 17th, 2021

DOI: https://doi.org/10.21203/rs.3.rs-887779/v1

License: (c) (1) This work is licensed under a Creative Commons Attribution 4.0 International License. Read Full License 


\section{Abstract \\ Background.}

Vaccine-induced immune thrombotic thrombocytopenia (VITT) is a rare syndrome of unclear aetiology occurring after DNA-based vaccinations against COVID-19. The aim of this study was to investigate the DNA vaccine-encoded Sars-cov-2 soluble spike protein (SP). as a potential trigger of platelet activation in VITT.

\section{Methods.}

We studied three VITT patients and seven healthy controls (HCs) within 3 weeks from the first dose of ChAdOx1 nCoV-19, and one non vaccinated HC. Serum levels of SP and soluble angiotensin-converting enzyme 2 (SACE2), ACE2 expression in platelets and platelet response to VITT serum stimulation were studied. A thrombus retrieved during mechanical thrombectomy from one VITT patients, was analysed by immunohistochemistry for SP and ACE2. Neutrophil extracellular traps (NETs) markers and coagulation parameters were also measured.

\section{Results.}

We detected serum SP (up to 35 days post-vaccination) and SACE2 in all VITT patients, and respectively in two and three out of 7 vaccinated HCs. Only platelets from one non-vaccinated HC expressed ACE2. VITT sera markedly activated platelets and this activation was inhibited by both anti-SP and antiFcyRIIA blocking antibodies. The thrombus showed positive immunohistochemical labelling of platelets using an anti-SP antibody with reduced ACE2 expression, compared to a thrombus from a pre-pandemic stroke patient. Markers of endothelial dysfunction, NETs and hypercoagulability state were present in all VITT sera.

\section{Conclusions.}

The present data provides first evidence that DNA vaccine-encoded Sars-cov-2 SP is detectable in VITT sera (several weeks post-vaccination) and in a plateletrich thrombus, and that may contribute to the initial platelet stimulation in VITT patients.

\section{Introduction}

Vaccine-induced immune thrombotic thrombocytopenia (VITT) is a recently described extremely rare ${ }^{1}$ but catastrophic syndrome, occurring 5 to 30 days after the first dose of the adenoviral vector-based vaccines, ChAdOx1 nCoV-19 and Covid-19 Janssen Vaccine, both encoding the full length of the Sars-cov-2 spike protein (SP). ${ }^{1-9}$ Although it resembles autoimmune heparin-induced thrombotic thrombocytopenia (HIT), due to the development of antibodies against the platelet factor 4 (PF4)-polyanion complexes, 2,10 the aetiopathogenesis and particularly the link between vaccination and the induction of anti-PF4 antibodies is still unknown.

Recent studies have ruled out a cross-reaction between the anti-Sars-cov2 SP antibodies and PF4 or PF4/heparin complexes, ${ }^{11}$ and no correlation has been detected between the levels of anti-PF4 and anti-SARS-CoV-2 neutralizing antibodies after ChAdOx 1 nCoV-19 vaccination, excluding the possibility that the anti-PF4 antibodies are a side-product of the physiological immune response to the vaccine. ${ }^{12}$ Structural studies have shown that the VITT anti-PF4 antibodies are different from the HIT anti-PF4 antibodies as they bind directly to the heparin-binding site on PF4, ${ }^{13}$ thus mimicking the effect of heparin in HIT, inducing immune complex formation and platelet stimulation. However, low-titre anti-PF4/polyanion antibodies were detected in some individuals who had received the ChAdOx1 nCoV-19 and even the mRNA vaccine Biontech/Pfizer, but had not experienced thrombosis or thrombocytopenia. ${ }^{14}$ Thus other vaccine components may be participating in platelet stimulation.

Pre-printed data indicate that ChAdOx1 nCoV-19 vaccine constituents can form antigenic complexes with PF4, inducing a potent anti-PF4 antibody production; notably EDTA, a vaccine ChAdOx1 nCoV-19 constituent, can increase microvascular permeability disseminating vaccine components into the blood stream and potentiating inflammatory response with antibody production and procoagulant neutrophil extracellular traps (NETs) formation (NETosis). ${ }^{15,16}$ ChAdOx 1 nCoV-19 vaccine contains also significantly higher amount of host cell protein impurities compared to the Covid-19 Vaccine Jansen explaining, at least in part, the higher incidence of VITT after ChAdOx1 nCoV-19. ${ }^{16}$

Sars-cov2 is an mRNA virus, not designed to be transcribed inside of the nucleus. Recently, it has been demonstrated that inside the nucleus adenoviral DNA can undergo to alternative splicing, which could lead to the synthesis of soluble SP variants with potentially serious side effects including platelet activation. ${ }^{17}$

In this study, we tested this hypothesis considering also that.VITT shares some characteristics with severe COVID-19 disease including: development of circulating platelet-activating immunocomplexes, NETosis, endothelial dysfunction, thrombocytopenia and thrombosis ${ }^{18-21}$. Moreover, since a possible prothrombotic role of Sars-coV-2 and its SP through ACE2 platelet receptors activation has been recently demonstrated in COVID-19 critically ill patients, ${ }^{18}$ we also tested the hypothesis that SP could activate platelets directly through its link with ACE2 receptors on platelets. 


\section{Study Cohort}

a) VITT Patients.

We studied three patients with VITT after ChAdOx 1 nCoV-19 vaccination. Data of patients 1 and 2 have been detailed elsewhere. ${ }^{22}$ Briefly, patient 1 was a $57-$ year-old woman with right middle cerebral artery (MCA) infarct, portal vein and pulmonary artery thrombosis and thrombocytopenia 9 days after vaccination. Anti-PF4/polyanion antibodies were initially negative, but high serum levels were found on day 15 from admission. She underwent endovascular thrombectomy and to decompressive craniotomy due to malignant MCA infarct. Effect of intravenous immunoglobulin on platelet count was striking but transient and she underwent three plasma exchange procedures from day 15 after admission. Thrombocytopenia remained stable for more than two months, and then platelet count slowly returned to normal values. On discharge, two months and 10 days after stroke onset, platelet count was 157,000 per mm ${ }^{3}$.

Patient 2 was a 55 year-old woman with bilateral malignant MCA infarcts, portal vein and pulmonary artery thrombosis, rapidly progressive thrombocytopenia (from 133.000 at onset 10 days after vaccination till $66.00048 \mathrm{~h}$ later) and high titer of anti-PF4/polyanion complexes. Brain death was declared $24 \mathrm{~h}$ later.

Patient 3 was a 59 year-old male affected by hypertension treated with an ACE inhibitor and a calcium channel blocker, who developed complete intraextrahepatic portal system and partial superior mesenteric vein thrombosis 11 days after vaccination. At admission he had severe thrombocytopenia $\left(15.000 / \mathrm{mm}^{3}\right)$, high levels of D-dimer and low level of fibrinogen. Anti-PF4 polyanion antibodies were positive on day 1 after hospital admission.

Main demographic, clinical and laboratory characteristics of the three patients are summarized in Table 1.

Table 1

Demographics, clinical and laboratory summary of patients with VITT on admission

\begin{tabular}{|c|c|c|c|c|c|c|c|c|c|c|c|c|}
\hline $\begin{array}{l}\text { VITT } \\
\text { Patient }\end{array}$ & Age & Sex & $\begin{array}{l}\text { Prexisting } \\
\text { Conditions }\end{array}$ & $\begin{array}{l}\text { Time from } \\
\text { Vaccine to } \\
\text { symptoms } \\
\text { (days) }\end{array}$ & $\begin{array}{l}\text { Ddimer } \\
(\mu \mathrm{g} / \mathrm{L}) \\
\text { (reference } \\
\text { value } \\
0-500 \text { ) }\end{array}$ & $\begin{array}{l}\text { FBG } \\
\text { (mg/dL) } \\
\text { (reference } \\
\text { value } \\
200- \\
400)\end{array}$ & $\begin{array}{l}\text { PLT } \\
\text { count } \\
\text { (per } \\
\mathrm{mm}^{3} \text { ) } \\
\text { (reference } \\
\text { value } \\
\begin{array}{l}150,000- \\
450,000 \text { ) }\end{array}\end{array}$ & $\begin{array}{l}\text { NETs } \\
\text { (ELISA) } \\
\mathrm{OD}_{405}\end{array}$ & $\begin{array}{l}\text { Anti- } \\
\text { PF4 } \\
\text { (ELISA) } \\
\mathrm{OD}_{405}\end{array}$ & $\begin{array}{l}\text { Site of } \\
\text { Thrombosis }\end{array}$ & $\begin{array}{l}\text { Treatment for } \\
\text { VITT }\end{array}$ & Ou \\
\hline 1 & 57 & $\mathrm{~F}$ & $\begin{array}{l}\text { Hypothyroidism } \\
\text { Previous breast } \\
\text { cancer }\end{array}$ & 9 & $>4318$ & 366 & 44,000 & 0.231 & Neg* & $\begin{array}{l}\text { Right MCA } \\
+\mathrm{PV}+ \\
\text { Pulmonary } \\
\text { arteries }\end{array}$ & $\begin{array}{l}\text { IVIG } \\
\text { Steroid } \\
\text { Fondaparinux } \\
\text { PE } \\
\text { PLT transf. }\end{array}$ & Fat \\
\hline 2 & 55 & $\mathrm{~F}$ & Hypothyroidism & 10 & 5441 & 336 & 133,000 & 1.696 & 1.29 & $\begin{array}{l}\text { Bilateral } \\
\text { MCA + PV+ } \\
\text { Pulmonary } \\
\text { arteries }\end{array}$ & $\begin{array}{l}\text { IVIG } \\
\text { Steroid }\end{array}$ & Fat \\
\hline 3 & 59 & $M$ & Hypertension & 9 & $>4309$ & 177 & 15,000 & 0.724 & 1.76 & $\begin{array}{l}\text { Intra- and } \\
\text { extra- } \\
\text { hepatic PV } \\
+ \\
\text { Partial } \\
\text { superior } \\
\text { mesentheric } \\
\text { vein }\end{array}$ & $\begin{array}{l}\text { IVIG } \\
\text { Steroid } \\
\text { Fondaparinux } \\
\text { PE } \\
\text { PLT transf. }\end{array}$ & $\operatorname{Rec}$ \\
\hline
\end{tabular}

(MCA: middle cerebral artery; PV: portal vein; PE: plasma exchange; PLT transf.: platelets transfusion; IVIG: intravenous immunoglobulin (1 gr/kg for 2 days). levels of anti-PF4 antibodies were found at day 24 from vaccination ( 1.68 optical density - $0 D_{405}$ )

\section{b) Vaccinated healthy controls.}

Seven voluntaries participated to this study. The median age was 37 (range 28-50); 1 of 7 was male. They received the first dose of ChAdOx 1 nCoV-19 within the previous 12 days (median; range $5-16$ ). Within $24 \mathrm{~h}$ from vaccination $5 / 7$ controls suffered from headache, $3 / 7$ developed fever (up to $39^{\circ} \mathrm{C}$ ), $4 / 7$ complained muscle pain at the site of vaccine inoculation and at both legs. All these symptoms resolved in a few days. Past medical history of all seven controls was unremarkable. Subject 5 was a light smoker. Nobody used to take prescription medicines.

\section{c) Non-vaccinated healthy control.}

One healthy non-vaccinated volunteer participated to this study. She was a 55-year old woman who suffered from hypertension treated with diuretics. 


\section{Ethics}

The study has been approved by the Ethics Committee of the University La Sapienza of Rome (study number 6305). All patients (or their representatives) and all volunteers provided written informed consent. Experimental procedures were conducted in accordance with the Declaration of Helsinki.

\section{Data Sharing}

Data will be made available to researchers upon reasonable request.

\section{Methods}

Blood samples from three VITT patients obtained within $72 \mathrm{~h}$ from admission and from seven vaccinated healthy controls (HCs) were used in this study. Blood was collected into serum silicone-coated tubes and centrifuged at $1500 \mathrm{G}$ for 15 minutes. Serum samples were aliquoted and stored at $-80^{\circ} \mathrm{C}$ until time of testing. Platelets taken from blood samples of VITT patient 3 , one vaccinated $\mathrm{HC}$ (control 6 ) and one non-vaccinated HC, were collected into tubes containing sodium citrate and treated for western blot.

Patient 1 serum was tested several times during hospitalization.

Coagulation Factors VIII and XIII, total levels of VWF-Antigen (VWF:Ag) and its capability to adhere to platelet glycoprotein complex GPIb-IX-V (VWF-Ristocetin Cofactor, VWF:RCo), were measured in all patients within $72 \mathrm{~h}$ from hospital admission and in all healthy vaccinated controls.

An enzyme-linked immunosorbent assay (ELISA) for IgG, IgA, and IgM antibodies (Immucor, Lifecodes, Waukesha, WI) against PF4-polyanion complexes (reference values, $<0.50$ OD units) was performed on VITT patient sera and on 2 out of 7 controls.

Further description of methodology is reported in the Supplementary material online.

\section{Results}

Diagnosis of VITT was based on the high levels of pan antibodies (IgG, IgM and IgA) to PF4-polyanion complexes (Table 1) and positivity of the seruminduced platelet function test. ${ }^{22,23}$ Controls showed neither anti-PF4 antibodies nor positive serum-induced platelet activation (Table 2). Coagulation parameters at admission were normal in all VITT patients except for a low fibrinogen level in patient 3 (Table 1). Factor XIII was markedly decreased and FVIII was slightly increased in VITT patients compared to vaccinated controls (Figure S1). None of the patients had laboratory findings suggestive of thrombotic thrombocytopenic purpura. All VITT patients showed evidence of endothelial activation with significantly elevated VWF:RCo as compared to vaccinated HCs (Figure S1). Serum markers of NETs were elevated in all patients compared to HCs, particularly in patient 2 (Table 1). In patient 1, serum markers of NETs were modestly increased upon admission, than decreased as the platelet count recovered and increased again as the platelet count dropped (Table S1). 
Table 2

Soluble Sars-cov-2 spike protein (SP), soluble ACE2 (SACE2), anti-PF4 antibodies dosed in serum collected within $72 \mathrm{~h}$ from hospital admission for VITT patients and within 16 days from first dose of ChAdOx1 nCov-19 vaccination in healthy controls.

\begin{tabular}{|c|c|c|c|c|}
\hline Study cohort & $\begin{array}{l}\text { Days from } \\
\text { vaccination } \\
\text { to samples }\end{array}$ & $\begin{array}{l}\mathrm{SP} \\
(\mathrm{pg} / \mathrm{ml})\end{array}$ & $\begin{array}{l}\text { sACE2 } \\
(\mathrm{ng} / \mathrm{ml})\end{array}$ & $\begin{array}{l}\text { Anti-PF4 (ELISA) } \\
\mathrm{OD}_{405}\end{array}$ \\
\hline Pt 1 & 9 & 0.869 & 1.1929 & 1.68 \\
\hline Pt 2 & 10 & 0.868 & 2.843 & 1.29 \\
\hline \multirow[t]{2}{*}{ Pt 3} & 15 & 1.165 & 32.876 & 1.76 \\
\hline & $\begin{array}{l}10 \\
\text { (median) }\end{array}$ & & & \\
\hline Control 1 & 12 & 0 & 0 & NA \\
\hline Control 2 & 14 & 0 & 0.533 & NA \\
\hline Control 3 & 12 & 2.6 & 1.0094 & 0.09 \\
\hline Control 4 & 16 & 1.88 & 2.561 & 0.41 \\
\hline Control 5 & 12 & 0 & 0 & NA \\
\hline Control 6 & 15 & 0 & 0 & NA \\
\hline \multirow[t]{2}{*}{ Control 7} & 5 & 0 & 0 & NA \\
\hline & $\begin{array}{l}12 \\
\text { (median) }\end{array}$ & & & \\
\hline $\begin{array}{l}\text { Reactivity on } \\
\text { available. OD: }\end{array}$ & rence value & ns that $t$ & not beer & $\mathrm{h}$ this methodology. Pt: patient. NA: no \\
\hline
\end{tabular}

All VITT serum samples showed detectable levels of soluble SP within $72 \mathrm{~h}$ from the index thrombotic event and 15 days from vaccination (median 10 days), whereas only 2 out of seven controls had measurable levels of serum SP within 16 days (median 12 days) from vaccination. Soluble ACE2 was also detectable in all VITT sera. Patient 3 presented the highest concentration of sACE2 (see Table 2). Among vaccinated HC, only three subjects showed detectable SACE2: the two subjects with the detectable SP and one patient without detectable SP.

Consecutive blood tests were performed for Patient 1 at different time points post-vaccination (Table S1). SP was still detectable at 35 days post-vaccination with values comparable to those detected at days 9 and 11. SACE2 level peaked on day 24 post-vaccination. Although a consistent reduction in ELISA reactivity for anti-PF4 antibodies was observed 20 days after plasma exchange, platelet functional activity test showed $20 \%$ ATP release after 20 minutes and this activation was reduced to $6 \%$ and $3 \%$ with low and high heparin concentration respectively.

ACE2 protein surface expression was absent on platelets obtained from patient 3 and from one vaccinated HC (Control 6), but was detected on platelets from a non-vaccinated HC (Fig. 1).

Sera from all 3 VITT patients induced the activation of platelets from healthy donors also in a distinct analysis evaluating the activation of integrin allb $\beta 3$ by flow cytometry. The anti-FcyRIIA blocking antibody inhibited the observed activation. To test the hypothesis that SP could bind to ACE2 receptors on platelets and synergize with the immune complexes/FcyRIIA pathway to induce platelet activation, we stimulated the platelets from healthy donors with patients' sera pre-incubated with an antibody targeting the S1 subunit of the SP. A partial inhibition of serum-induced platelet integrin activation was observed, reaching statistical significance in patient 1 (Fig. 2).

Histological features of clots retrieved during the two subsequent mechanical thrombectomies in patient 1 were already described.$^{22}$ The clot collected during the first thrombectomy was a "white" thrombus (Figure S2) mainly composed of platelets massively infiltrated by neutrophils (Fig. 3A). Double staining with anti-CD 61 (platelet marker) and anti-Sars-cov-2 SP antibodies showed co-localization of the two antigens (Fig. 3A). Immunohistochemistry showed weak but diffuse Sars-cov-2 SP staining which co-localized with ACE2 staining (Fig. 3B). A thrombus retrieved from a pre-pandemic age- and sex-matched stroke patient showed a stronger diffuse staining for ACE2 (Fig. 3H) but no evidence of staining for SP (Fig. 3I).

\section{Discussion}

Emerging evidence suggests that platelet activation in VITT is mediated by the production of anti-PF4/polyanion antibodies followed by generation of IgG/PF4/polyanion immunocomplexes, massive neutrophil activation and release of NETs, endothelial activation and eventually diffuse venous and arterial thrombosis. ${ }^{15,24}$ Although the adenoviral vector has been proposed as the first trigger of platelet activation, this hypothesis is still unproven. Here, we provide evidence for an alternative mechanism that may generate a cascade of events culminating in full-blown VITT. 
We have detected the Sars-cov-2 SP in serum of three VITT patients within $72 \mathrm{~h}$ from the index thrombotic event up to 35 days from vaccination, suggesting that these patients might be experiencing a prolonged/excessive production of the SP. We also observed that the SP co-localized with platelets in sections of the "white" arterial thrombus retrieved by Patient 1. As far as we know, this is the first evidence of SP inside a retrieved thrombus in VITT.

It has been demonstrated that Sars-cov-2 and the SP alone can directly activate platelets via ACE2/SP interaction and that platelet activation is suppressed by the recombinant human ACE2 protein and anti-SP monoclonal antibody. ${ }^{18}$ Accordingly, we have found a partial suppression of platelet integrin activation in all VITT patients by using an antibody directed against the Sars-cov- 2 spike protein S1 subunit. Since stimulation of platelets by SP leads to PF4 release, ${ }^{18}$ it could then trigger platelet activation by forming IgG/PF4/polyanion immunocomplexes in individuals that express high levels of andi-PF4 antibodies.

A progressive reduction of ACE2 expression on platelets of critically ill COVID-19 patients and on platelets incubated with the Sars-cov-2,18 as well as on alveolar epithelial cells incubated with purified Sars-cov recombinant $\mathrm{SP}_{1}^{25}$ has been observed. This evidence suggest a possible internalization and subsequent degradation ${ }^{18}$ or cleavage (or shedding) ${ }^{26,27}$ of the ACE2 receptor induced by the Sars-Cov- 2 and purified SP. We found ACE2 protein expressed on platelets of non-vaccinated HC, but not on those collected from a VITT patient, and ACE2 expression level was lower on platelets inside the VITT thrombus compared with a pre-pandemic control thrombus. Although limited to few subjects, these observations suggest a possible ACE2 receptor down-regulation on platelets in VITT. We detected SACE2 in serum from all three VITT patients with the highest levels in patient 3 who suffered from hypertension and used to take an ACE-inhibitor medication. Levels of ACE2, the main host cell receptor for the Sars-cov2, in human body is probably genetically determined. ${ }^{28}$ Besides its membrane form, which drives the virus into the host cell, a soluble ACE2 is well known, in part resulting from proteolytic cleavage and ectodomain shedding. ${ }^{26,27}$ Recently, although high levels of sACE2 have been observed in critically ill COVID-19 patients, a possible neutralizing and protective effect of SACE2 on virus spreading into the bloodstream has been hypothesized, ${ }^{29,30}$ and clinical trials in COVID-19 with human recombinant soluble ACE2 are ongoing (https://www.clinicaltrials.gov; NCT04287686). In this regard, it is interesting that only patient 3, whose sACE2 levels were quite high, recovered from VITT.

Based on our data we postulate a multiple-hit model for platelet activation in VITT aetiopathogenesis. The first hit being the direct interaction between the Sars-cov-2 SP and the ACE2 receptors on platelets and endothelial cells. Activated endothelial cells would induce platelet recruitment and adhesion by exposing adhesion receptors and releasing VWF. Activated platelets would release their granular contents which include large amounts of PF4 and enable the formation of immune complexes in individuals expressing high levels of anti-PF4 antibodies. The second hit being the stimulation of FcgRIIA by $\mathrm{IgG/PF} 4 /$ polyanion immune complexes resulting in the amplification of platelet activation; the third hit being the stimulation of neutrophils by IgG/PF4/polyanion immune-complexes and platelets, resulting in the release of NETs which in turn stimulates coagulation and platelets. ${ }^{15,24}$ Interestingly, patient 2 whose clinical course was rapidly fatal showed the highest level of NETs. A support to this 3-hit hypothesis is also the finding that despite the negativity of anti-PF4 antibodies at 35 days from admission, patient 3 serum continued to activate healthy donors' platelets and still had detectable levels of soluble SP in the serum.

Some observations on vaccinated HCs need consideration. Unexpectedly, we found SP in serum of 2 out of 7 vaccinated HCs within 16 days from the first dose of ChAdOx1 nCoV-19. Both of them presented also detectable levels of sACE2. Neither of these two controls presented anti-PF4 antibodies, nor their sera could activate platelets from healthy donors. We can hypothesize that soluble SP variants capable of activating platelets are produced very rarely from alternative splicing events. A lower ACE2 receptor expression on platelets, possibly genetically-determined, could also justify the different chance of platelets to be activated by soluble SP. Other authors have found the full length SP and S1 subunit in plasma of respectively $3 / 13$ and $11 / 13$ healthy subjects who received the first dose of mRNA-1273 vaccine (Moderna), ${ }^{31}$ but clearance of both proteins correlated with IgG and IgA production. The clinical significance of this and our finding in $\mathrm{HC}$ is still unknown and more studies are warranted, but it seems to represent a harmless phenomenon.

One limitation of our study is the small number of participants. A second limitation is that we have not quantified the Sars-cov-2 nuclear antigen in serum to rule out a possible Sars-cov-2 infection, nor performed a Sars-cov-2 RNA in situ hybridization in addition to immunohistochemistry on thrombus of patient 1. However, all three patients were assessed to be negative for COVID-19 infection by rRT-PCR test on nasopharyngeal swab and patient 2 also on bronchoalveolar lavage. Serum antibodies to SP $(\operatorname{lgG})$ were positive only in patient 1 suggesting an asymptomatic previous infection.

In conclusion, the present data provides first evidence that 1) DNA vaccine-encoded Sars-cov-2 soluble SP is detectable in VITT patients' serum up to several weeks post-vaccination; 2) SP appears to co-localize with platelets in a thrombus retrieved from a VITT patients; 3) ACE2 expression on platelets seems to be reduced in VITT patients; 4) anti-SP antibody can partially inhibit platelets activated by VITT sera. All this data suggest that SP may be one of the platelet activation triggers in VITT via binding to ACE2 receptors expressed on platelets, and in part on endothelium. Anti-PF4/polyanion antibodies development could represent an epiphenomenon, which amplifies platelet aggregation, NETosis and coagulation cascade. This data needs to be confirmed by studies on larger samples of subjects.

\section{References}

1. Pavord S, Scully M, Hunt BJ, et al. Clinical Features of Vaccine-Induced Immune Thrombocytopenia and Thrombosis. N Engl J Med 2021.

2. Greinacher A, Thiele T, Warkentin TE, Weisser K, Kyrle PA, Eichinger S. Thrombotic Thrombocytopenia after ChAdOx1 nCov-19 Vaccination. N Engl J Med 2021;384:2092-101.

3. Schultz NH, Sørvoll IH, Michelsen AE, et al. Thrombosis and Thrombocytopenia after ChAdOx1 nCoV-19 Vaccination. N Engl J Med 2021;384:2124-30.

4. Scully M, Singh D, Lown R, et al. Pathologic Antibodies to Platelet Factor 4 after ChAdOx1 nCoV-19 Vaccination. N Engl J Med 2021;384:2202-11.

5. Muir KL, Kallam A, Koepsell SA, Gundabolu K. Thrombotic Thrombocytopenia after Ad26.COV2.S Vaccination. N Engl J Med 2021;384:1964-5.

6. Sadoff J, Davis K, Douoguih M. Thrombotic Thrombocytopenia after Ad26.COV2.S Vaccination - Response from the Manufacturer. N Engl J Med 2021;384:1965-6.

Page 6/9 
7. See I, Su JR, Lale A, et al. US Case Reports of Cerebral Venous Sinus Thrombosis With Thrombocytopenia After Ad26.COV2.S Vaccination, March 2 to April 21, 2021. Jama 2021;325:2448-56.

8. Karron RA, Key NS, Sharfstein JM. Assessing a Rare and Serious Adverse Event Following Administration of the Ad26.COV2.S Vaccine. Jama 2021;325:2445-7.

9. Perry RJ, Tamborska A, Singh B, et al. Cerebral venous thrombosis after vaccination against COVID-19 in the UK: a multicentre cohort study. Lancet 2021.

10. Greinacher A, Selleng K, Warkentin TE. Autoimmune heparin-induced thrombocytopenia. J Thromb Haemost 2017;15:2099-114.

11. Greinacher A, Selleng K, Mayerle J, et al. Anti-Platelet Factor 4 Antibodies Causing VITT do not Cross-React with SARS-CoV-2 Spike Protein. Blood 2021.

12. Uzun G, Althaus K, Bakchoul T. No Correlation between Anti-PF4 and Anti-SARS-CoV-2 Antibodies after ChAdOx1 nCoV-19 Vaccination. N Engl J Med 2021.

13. Huynh A, Kelton JG, Arnold DM, Daka M, Nazy I. Antibody epitopes in vaccine-induced immune thrombotic thrombocytopaenia. Nature 2021;596:565-9.

14. Thiele T, Ulm L, Holtfreter S, et al. Frequency of positive anti-PF4/polyanion antibody tests after COVID-19 vaccination with ChAdOx $1 \mathrm{nCoV}-19$ and BNT162b2. Blood 2021;138:299-303.

15. Towards Understanding ChAdOx1 nCov-19 Vaccine-induced Immune Thrombotic Thrombocytopenia (VITT). 2021.

16. Comparative analysis of ChAdOx1 nCoV-19 and Ad26.COV2.S SARS-CoV-2 vector vaccines. 2021.

17. "Vaccine-Induced Covid-19 Mimicry" Syndrome:Splice reactions within the SARS-CoV-2 Spike open reading frame result in Spike protein variants that may cause thromboembolic events in patients immunized with vector-based vaccines. 2021.

18. Zhang S, Liu Y, Wang X, et al. SARS-CoV-2 binds platelet ACE2 to enhance thrombosis in COVID-19. J Hematol Oncol 2020;13:120.

19. Nazy I, Jevtic SD, Moore JC, et al. Platelet-activating immune complexes identified in critically ill COVID-19 patients suspected of heparin-induced thrombocytopenia. J Thromb Haemost 2021;19:1342-7.

20. Zuo Y, Yalavarthi S, Shi H, et al. Neutrophil extracellular traps in COVID-19. JCl insight 2020;5.

21. Iba T, Levy JH, Connors JM, Warkentin TE, Thachil J, Levi M. The unique characteristics of COVID-19 coagulopathy. Crit Care 2020;24:360.

22. De Michele M, lacobucci M, Chistolini A, et al. Malignant cerebral infarction after ChAdOx1 nCov-19 vaccination: a catastrophic variant of vaccine-induced immune thrombotic thrombocytopenia. Nat Commun 2021;12:4663.

23. Guarino ML, Massimi I, Mardente S, et al. New platelet functional method for identification of pathogenic antibodies in HIT patients. Platelets 2017;28:728-30.

24. Holm S, Kared H, Michelsen AE, et al. Immune complexes, innate immunity, and NETosis in ChAdOx1 vaccine-induced thrombocytopenia. Eur Heart J 2021.

25. Kuba K, Imai Y, Rao S, et al. A crucial role of angiotensin converting enzyme 2 (ACE2) in SARS coronavirus-induced lung injury. Nature medicine $2005 ; 11: 875-9$.

26. Heurich A, Hofmann-Winkler H, Gierer S, Liepold T, Jahn O, Pöhlmann S. TMPRSS2 and ADAM17 cleave ACE2 differentially and only proteolysis by TMPRSS2 augments entry driven by the severe acute respiratory syndrome coronavirus spike protein. J Virol 2014;88:1293-307.

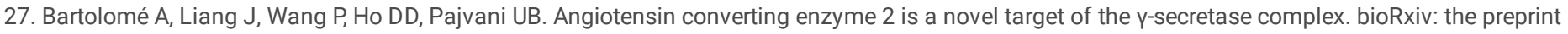
server for biology 2020.

28. Rice GI, Jones AL, Grant PJ, Carter AM, Turner AJ, Hooper NM. Circulating activities of angiotensin-converting enzyme, its homolog, angiotensin-converting enzyme 2, and neprilysin in a family study. Hypertension (Dallas, Tex: 1979) 2006;48:914 - 20.

29. Ciaglia E, Vecchione C, Puca AA. COVID-19 Infection and Circulating ACE2 Levels: Protective Role in Women and Children. Front Pediatr $2020 ; 8: 206$.

30. Monteil V, Kwon H, Prado P, et al. Inhibition of SARS-CoV-2 Infections in Engineered Human Tissues Using Clinical-Grade Soluble Human ACE2. Cell 2020;181:905 - 13.e7.

31. Ogata AF, Cheng CA, Desjardins M, et al. Circulating SARS-CoV-2 Vaccine Antigen Detected in the Plasma of mRNA-1273 Vaccine Recipients. Clin Infect Dis 2021.

\section{Figures}

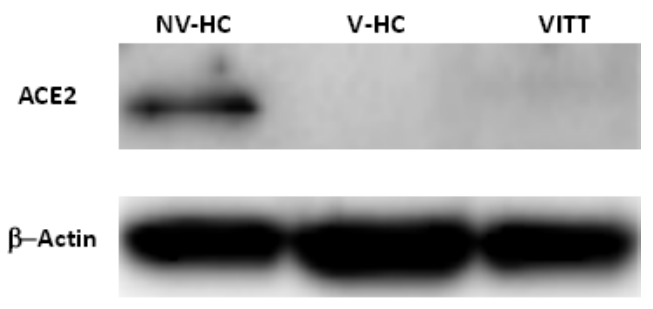

\section{Figure 1}

Platelet ACE2 was detected in platelets from one non vaccinated healthy control (NV-HC), whereas it was not detected in one vaccinated-healthy control (control 6; V-HC) and in patient 3 (VITT). The ACE2 protein levels were detected by Western blot. A representative image of 3 experiments is showed. $\beta$-actin has been used as loading control. 


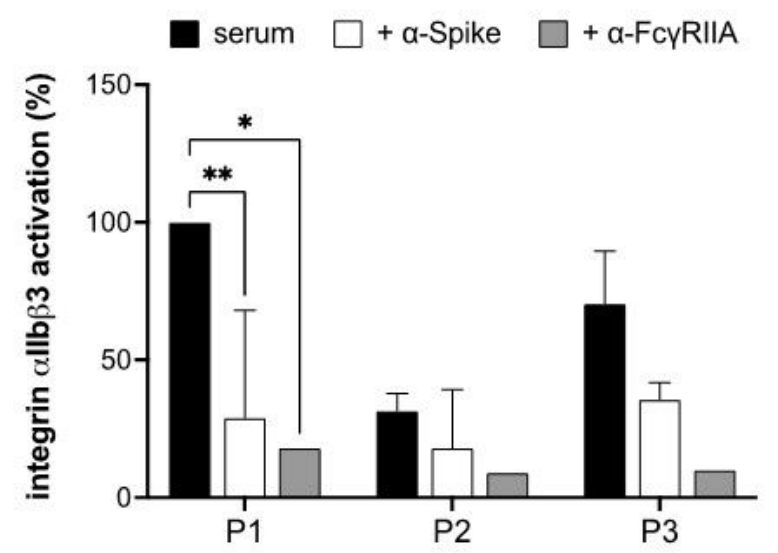

Figure 2

Serum-induced platelet activation evaluated through the activation of integrin allb $\beta 3$ by flow cytometry was inhibited by the FcyRIIA blocking antibody ( $\mathrm{a}-$ FcyRIIA) in all patients and was decreased by an antibody anti Sars-cov-2 spike protein (a-Spike). Summary data of 3 experiments are presented using pooled platelets from three different healthy donors. Statistical analyses were performed using two-way Anova with Tukey's multiple comparisons test. *P $<0.05$; $* \star P$ < 0.01. P1: patient 1; P2: Patient 2; P3: Patient 3

A

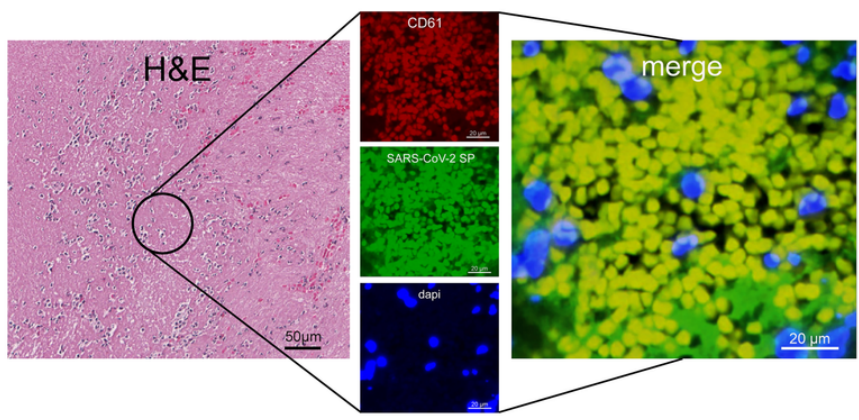

B

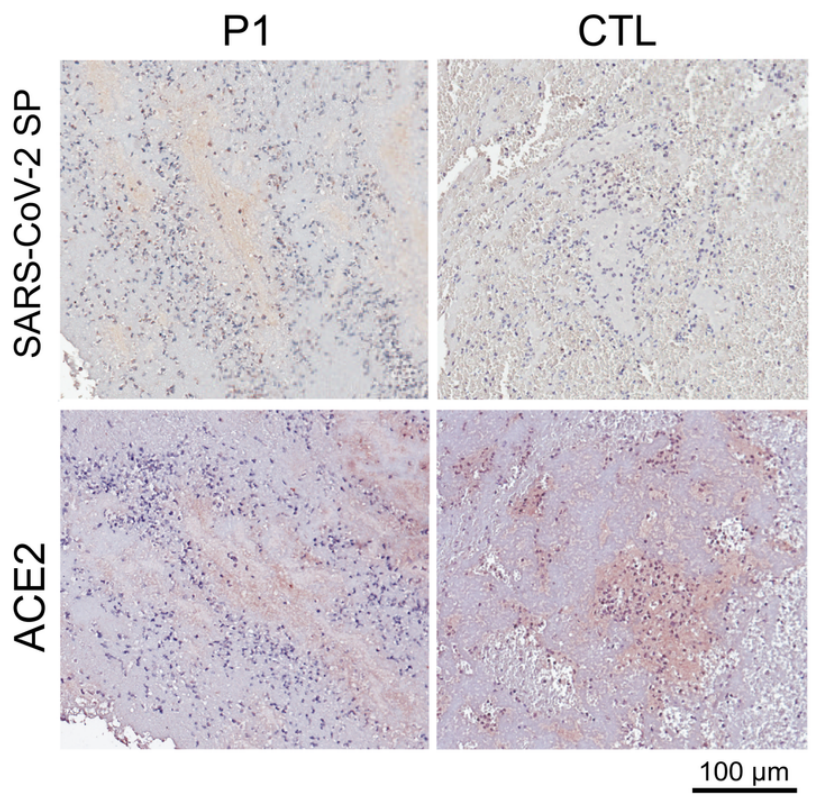

Figure 3

Thrombus from VITT patient 1 was rich in platelets and stained positive for Sars-cov-2 Spike protein (SP) and ACE2 A. Double immunofluorescence of thrombotic material retrieved from right middle cerebral artery of Patient 1 during the first mechanical thrombectomy. On hematoxylin-eosin stain (H\&E), the thrombus was made up almost exclusively by platelets, with abundant granulocytes. Platelets within the area encircled in A are stained in red with CD61 
antibodies, the SARS-CoV-2 SP is stained in green, while the nuclei of the inflammatory cells are stained in blue with DAPI. Overlap of SARS-CoV-2 SP and platelets is shown in yellow (merge). B. Immunohistochemistry highlights the presence of SARS-CoV-2 SP associated with decreased amounts of ACE2, within the thrombus of Patient 1 (P1) as compared with a thrombus retrieved from a patient in the pre-pandemic era (CTL).

\section{Supplementary Files}

This is a list of supplementary files associated with this preprint. Click to download.

- SupplementaryAppendix.docx 